\title{
Correction to: Parameters Affecting the Precipitation of Al Phases from Aluminate Solutions of the Pedersen Process: The Effect of Carbonate Content
}

\author{
Danai Marinos $^{1}$ D $\cdot$ Michail Vafeias $^{1} \cdot$ Dimitris Sparis $^{1} \cdot$ Dimitris Kotsanis $^{1} \cdot$ Efthymios Balomenos $^{1,2} \cdot$ Dimitris Panias $^{1}$
}

Published online: 17 August 2021

(c) The Minerals, Metals \& Materials Society 2021

\section{Correction to: Journal of Sustainable Metallurgy https://doi.org/10.1007/s40831-021-00403-w}

As a result of an error during the publication process, the graphic for Fig. $2 b$ in this article as originally published was incorrect. The correct graphic is presented below.

The original article has been corrected

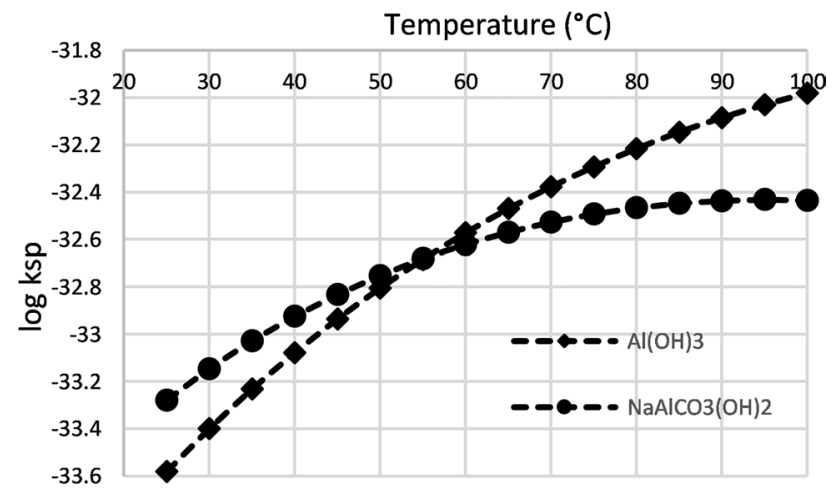

Fig. 2 a Aluminum speciation diagram of PLS, b Solubility product constant $\left(k_{\mathrm{sp}}\right)$ of aluminum hydroxide $\left(\mathrm{Al}(\mathrm{OH})_{3}\right)$ and dawsonite $\mathrm{NaAlCO}_{3}(\mathrm{OH})_{2}$ versus temperature. [where $\mathrm{a}=$ aqueous, $\mathrm{a}-$ aqueous anion, a+ aqueous cation]

The original article can be found online at https://doi.org/10.1007/ s40831-021-00403-w.

Danai Marinos

dmarinou@metal.ntua.gr

1 School of Mining and Metallurgical Engineering, National Technical University of Athens, 9 Iroon Polytechneiou str., Athens, Greece

2 Metallurgy Business Unit, Mytilinaios S.A., Agios Nikolaos, Voiotia, Greece
Publisher's Note Springer Nature remains neutral with regard to jurisdictional claims in published maps and institutional affiliations. 